Research Article

\title{
Determinants of Active Tuberculosis Occurrences after ART Initiation among Adult HIV-Positive Clients in West Showa Zone Public Hospitals, Ethiopia: A Case-Control Study
}

\author{
Gerbaba Guta Nugus $\mathbb{D}^{1}$ and Mergitu Eliyas Irena ${ }^{2}$ \\ ${ }^{1}$ Department of Public Health, College of Medicine and Health Sciences, Ambo University, Ambo, Ethiopia \\ ${ }^{2}$ Department of Nursing, College of Medicine and Health Sciences, Ambo University, Ambo, Ethiopia \\ Correspondence should be addressed to Gerbaba Guta Nugus; gerbaba.guta@ambou.edu.et
}

Received 11 November 2019; Revised 8 January 2020; Accepted 15 May 2020; Published 31 May 2020

Academic Editor: Julio Diaz

Copyright (c) 2020 Gerbaba Guta Nugus and Mergitu Eliyas Irena. This is an open access article distributed under the Creative Commons Attribution License, which permits unrestricted use, distribution, and reproduction in any medium, provided the original work is properly cited.

\begin{abstract}
Introduction. Tuberculosis is a major public health concern globally, especially in sub-Saharan African countries. It is the most common opportunistic infection and leading cause of mortality among people living with human immunodeficiency virus despite increased deliverance of antiretroviral therapy. Objectives. The aim of this study was to identify determinants of active tuberculosis among adult HIV positive patients after ART initiation in West Showa Zone public hospitals, Ethiopia. Methods. Multicentred unmatched casecontrol study was conducted on selected public hospitals in West Showa Zone from February to June, 2019. A total of 406 participants (203 cases and 203 controls) were included in the study. Cases were adult HIV patients who developed tuberculosis after ART initiation while controls were adult HIV patients who did not develop tuberculosis after ART initiation. Data were collected using interviewer administered structured questionnaire. Logistic regression analysis was performed using SPSS version 24 statistical software. Statistical significance test was set at 95\% confidence level. Results. This study identified that patient's previous TB history (AOR $=2.41 ; 95 \%$ CI: 1.49, 3.90; $\mathrm{P}$ value $<0.001)$, haemoglobin level $(\mathrm{AOR}=3.67 ; 95 \% \mathrm{CI}: 1.98,6.79$; $\mathrm{P}$ value $<0.001)$, $\mathrm{CD} 4$ cells count $(\mathrm{AOR}=2.02$; $\mathrm{CI}$ : 1.24 , 3.29; $\mathrm{P}$ value $=0.004)$, adherence level $(\mathrm{AOR}=19.00$; $\mathrm{CI}: 5.59,64.59 ; \mathrm{P}$ vaue $<0.001)$, and WHO HIV/AIDS clinical stage (AOR = 2.58; $\mathrm{CI}$ : $1.59,4.18$; P vaue $<0.001$ ) were found to be statistically significant determinants for the occurrence of tuberculosis among PLHIV after ART initiation. Conclusion. Patient's previous TB history, haemoglobin level, CD4 cells count, adherence level, and WHO clinical stage were significant determinants of occurrence of tuberculosis after ART initiation in PLHIV.
\end{abstract}

\section{Introduction}

Tuberculosis (TB) is an infectious disease caused by the bacillus Mycobacterium tuberculosis that typically affects the lungs (pulmonary TB) but can also affect other sites (extrapulmonary TB) [1]. Tuberculosis spreads from person to person by airborne transmission when the infected person is talking, coughing, sneezing, laughing, or singing [1].

Tuberculosis is the most common presenting illness among people living with HIV, including those who are taking antiretroviral treatment $[2,3]$. Among opportunistic infections, TB is the most frequent life threatening and a leading cause of death of PLHIV [3]. TB/HIV coinfection affects patients' quality of life leading to poor physical health and mental disorders compared to HIV infected individuals [4]. TB and HIV are called a "deadly duo" as HIV weakens the immune system and makes them more susceptible for TB infection and TB increases the progression of HIV to AIDS stage [5]. A study reveals that HIV complicates the follow-up and compromises the response to anti-TB treatment. The complication of treatment outcomes of both diseases results from the simultaneous use of antiretroviral treatment (ART) and intensive phase of TB treatment [6].

Tuberculosis has continued being major public health problem globally affecting almost one-third of HIV infected patients. Global tuberculosis report listed TB among the top 10 causes of death and described it as the leading cause from a single infectious agent (HIV/AIDS). Even though TB affects all countries and all age groups, the estimate of 2017 
revealed that $90 \%$ of the cases were adults (aged $\geq 15$ years) and 9\% were people living with HIV (72\% of them in Africa) [1].

In high HIV prevalent countries, HIV related TB continues to be increasing even in well-established TB program [7]. Human immunodeficiency virus (HIV) is reported as a major contributing factor for developing active TB. For instance, a study has shown that HIV-infected individuals are at higher risk of developing tuberculosis than HIV-negative individuals [8]. Additionally, high burden $\mathrm{TB}$ has been destroying the successes recorded on HIV-infection treatment as a result of ART even after the initiation of ART [2].

Therefore, TB is currently becoming a major cause of mortality among patients with HIV even after successful initiation of HAART [9]. According to 2018 WHO report, out of 1.3 million deaths due to TB in 2017, there were 300,000 deaths from TB among HIV-positive people [1].

It has been reported that, in sub-Saharan Africa including Ethiopia, the incidence of tuberculosis in adults receiving highly active antiretroviral therapy is higher than in HIVnegative adults [1]. Ethiopia is also among high TB/HIV burden countries with over $10 \% \mathrm{~TB} / \mathrm{HIV}$ coinfection rate [3]. Evidences show that there is an increment of active TB in HIV patient on HAART follow-up in Ethiopia. TB-HIV sentinel surveillance of 2013 shows that TB prevalence was 7.8\% among HIV-positive clients [7]. However, TB prevalence among PLWHIV was raised to $9.1 \%$ in 2015. TB prevalence among PLWHIV varies among different regions of the country ranging from $5.0 \%$ in Afar to $14.2 \%$ in Harar [8].

Several studies were conducted in the country on TB prevalence and its associated factors among HIV patients. However, there are limited studies on determinants of TB occurrence among HIV patients after ART initiation. Therefore, the objective of this study was to identify determinants of active tuberculosis occurrence among adult HIV-positive patients after ART initiation in West Showa Zone public hospitals, using a case-control study design.

\section{Materials and Methods}

2.1. Study Area and Period. The study was conducted in West Showa Zone selected hospitals, Oromia regional state of Ethiopia, from February to June, 2019. According to the 2007 census of Ethiopia, the total population of the West Showa zone was estimated to 2,058,676, of which 1,028,501 are males and $1,030,175$ are females. In this zone, there are 520 health posts, 92 health centres, and 7 hospitals. This study was conducted in three public hospitals randomly selected from seven hospitals in the administrative zone. These selected hospitals include Ambo General Hospital, Gudar Hospital, and Incini Hospital. There were 4750 adult HIV clients attending in these selected hospitals in which there were 750 in Gudar Hospital, 3000 in Ambo General Hospital, and 1000 in Incini Hospital.

2.2. Study Design. Institution-based multicentred unmatched case-control study design was used.

2.3. Source Population. All adult HIV patients on ART clinic were followed up in West Showa Zone hospitals.
2.4. Study Population. Adult HIV patients on ART clinic were followed up in selected West Showa Zone hospitals during the study period.

\subsection{Cases and Controls Inclusion Criteria}

2.5.1. Cases Inclusion Criteria. Cases who met the following eligibility criteria were included:

(i) Patients who were willing to participate in the study

(ii) Patients who were $\geq 18$ years old

(iii) Patients who were free from $\mathrm{TB}$ at the start of ART but developed TB after ART initiation

2.5.2. Case Exclusion Criteria. Cases were excluded with the following criteria:

(i) Patients who were unable to give informed consent or follow interview because of serious illness or other reasons

(ii) Patients who were transferred out to other ART clinics

(iii) Patients whose medical record has incomplete information

(iv) Patients who were lost to follow-up

2.5.3. Control Inclusion Criteria. Controls were included with the following eligibility criteria:

(i) Patients who were willing to participate in the study

(ii) Patients who were free from TB since the start of ART up to the end of the study period

(iii) Patients who were at least 18 years old

2.5.4. Control Exclusion Criteria. Controls were excluded with the following criteria:

(i) Patients who were unable to give informed consent or follow interview because of serious illness or other reasons

(ii) Patients who were transferred out to other ART clinics

(iii) Patients whose medical record was incomplete

(iv) Patients who were lost to follow-up

2.6. Sample Size Determination. The sample size was calculated by Open Source Epidemiologic Calculator, OpenEpi version 3.01, 2016 (available from https://www.openepi. com/SampleSize/SSCC.htm) using the following parameters: proportion of HIV/AIDS patients among controls with CD $4<200$ cells $/ \mathrm{ml}$ of $15.7 \%$ [10], two-sided $5 \%$ significance level, power of $80 \%$, controls to cases ratio of $1: 1$, and minimum odd ratio to be detected which was 2 . Accordingly, the minimum required sample size was 406 (203 cases and 203 controls). In the sample size determination, CD $4<200$ cells $/ \mathrm{ml}$ was considered as exposure status for 
active TB occurrence among HIV patients after ART initiation since it was reported in most literatures for being predictor of TB.

2.7. Sampling Technique and Procedure. In the study area, 7 hospitals provide HIV care services. Out of the 7 hospitals, 3 of them were selected by simple random sampling method. Accordingly, Gudar Hospital, Ambo General Hospital, and Incini Hospital were included in this study. Then, identification of cases and controls was done from ART and TB registries in each hospital. In the three selected hospitals, there were a total of 240 cases: 30 cases in Gudar Hospital, 160 cases in Ambo General Hospital, and 50 cases in Incini Hospital. In these hospitals there were a total of 4510 controls: 720 in Gudar Hospital, 2840 in Ambo General Hospital, and 950 in Incini Hospital. Thus, required sample size $(n=406)$ was selected from the three selected hospitals. The number of cases and controls included in the study was determined by proportional allocation method for each hospital. Accordingly, 26 cases and 32 controls from Gudar Hospital, 135 cases and 128 controls from Ambo General Hospital, and 42 cases and 43 controls from Incini Hospital were included in this study. Since controls were adequate enough to be sampled, required number of samples from each hospital was selected by using systematic random sampling selecting every $22^{\text {th }}(4510 / 203)$ patient on medical record lists.

\subsection{Variables of the Study}

2.8.1. Dependent Variable. This was the status of active tuberculosis after ART initiation.

\subsubsection{Independent Variables}

(i) Sociodemographic Characteristics. These were sex, age, marital status, educational status, employment status, residence, income, and family size

(ii) Clinical and Immunological Characteristics. These were previous TB disease status, WHO clinical stage, CD4 level, viral load, haemoglobin level, ART regimen, IPT prophylaxis use, CTX prophylaxis use, adherence level, and functional status

(iii) Environmental Factors. These were family's previous TB history, source of energy used in the house, and ownership of separate kitchen

(iv) Comorbidity. This was status of diabetic mellitus and/or asthma

(v) Behavioural Characteristics. These were tobacco smoking status, alcohol drinking status, and chat chewing status.

(vi) Nutritional Status. This was body mass index/ MUAC

\subsection{Operational Definitions}

(i) Cases. These were defined as HIV/AIDS patients who had developed TB after HAART initiation (ii) Controls. These were defined as HIV/AIDS patients who were on HAART follow-up and did not develop TB until the end of the study period

(iii) Functional Status. It is classified into the following:

(a) Working = able to perform usual work in or out of the house

(b) Ambulatory = able to perform activities of daily living

(c) Bedridden $=$ not able to perform activities of daily living

(iv) Adherence Level Classification. It was done according to HIV Case Management in Ethiopia (Table 1) [11]

2.10. Source of Data and Data Collection Instrument. Data were collected from both primary and secondary sources. From primary source, data were collected by three trained nurses through interviewer administered structured questionnaire addressing sociodemographic characteristics, environmental factors, and behavioural characteristics of the patients. Then, information about clinical and immunological characteristics, comorbidity status, and nutritional status of the patients was taken from the secondary source (patients' HIV medical record and TB registration book).

2.11. Statistical Data Analysis. The collected data were entered in to EpiData version 4.2, and further data analysis was done using SPSS version 24. Frequencies and proportions were used to describe the study population in relation to relevant variables. Logistic regression model was fitted to identify determinants of active TB among PLWHIV. Variable with $P$ value $\leq 0.25$ during bivariable analysis was considered as a candidate for the multivariable model fitting. In the multivariable logistic regression model fitting, AOR with 95\% confidence interval was computed. Statistical significant test for each independent variable was set at $P$ value $<0.05$.

2.12. Ethical Consideration. Ethical clearance was obtained from ethical review committee of Ambo University, College Medicine, and Health Sciences. Then, permission was also obtained from the administrative body of each hospital to access the tuberculosis and ART patient's medical record charts. Additionally verbal consent was also obtained from the study participants to confirm their willingness for participation after explaining the objective of the study. Confidentiality of the participants was maintained by not recording the information that describes the identity of the individuals.

\section{Results}

3.1. Sociodemographic Characteristics. In this study, a total of 406 study participants from three ART centres, 203 cases and 203 controls with response rate of $100 \%$, were analyzed. The baseline mean age of interviewed study participants was 
TABLE 1: Level of adherence of determinants of active tuberculosis occurrence among adult HIV-positive patients after ART initiation in West Showa Zone public hospitals.

\begin{tabular}{lccc}
\hline Adherence level & Score $(\%)$ & Doses missed from 30 doses & Doses missed from 60 doses \\
\hline Good & $>95 \%$ & $\leq 2$ doses & $<3$ doses \\
Fair & $85-94 \%$ & $3-5$ doses & $3-9$ doses \\
Poor & $<85 \%$ & $\geq 6$ doses & $>9$ doses \\
\hline
\end{tabular}

$33.1(\mathrm{SD}= \pm 8.9)$ for cases and $34.3(\mathrm{SD}= \pm 8.1)$ for controls ranging between 18 and 64 years. More proportions of case and control patients were in the age group of 30-39 years comprising 79 (38.9\%) and 103 (50.7\%), respectively. Slightly more than half, 224 (55.2\%) of the study participants were females. A majority of the study participants were Oromo ethnic group $164(80.8 \%)$ in cases and $181(89.2 \%)$ in controls. According to the religion of the participants, a majority of the cases $146(71.9 \%)$ and controls $118(58.1 \%)$ were Orthodox, while 47 (23.2\%) of the cases and 78 (38.4\%) of the controls were Protestant (Table 2).

\subsection{Environmental and Behavioural Characteristics,} Comorbidity, and Nutritional Status of the Study Participants. Among the total study participants, about $20 \%$ of the cases and $14 \%$ of the controls had family with a previous history of TB. A majority of the study participants 194 (95.6\%) of cases and 199 (98.0\%) of controls have had separate kitchen and both groups rarely $7(1.7 \%)$ used kerosene as a source of energy. Khat chewing and tobacco smoking were not common in both cases and controls. Regarding alcohol drinking characteristics, $82(40.4 \%)$ of the cases and 74 (36.5\%) controls were drinkers. Comorbidity was rare in both cases and controls. In case of nutritional status, 129 (63.5\%) of the cases and $130(64.0 \%)$ the controls of the study participants have had body mass index (BMI) between 18.5 and 25 (Table 3).

3.3. Clinical and Immunological Characteristics of the Study Participants. From the total study participants, 134 (66\%) of the cases and $76(37.4 \%)$ of the controls had previous TB history. Among cases 68 (33.5\%) of them had haemoglobin level less than $10 \mathrm{mg} / \mathrm{dl}$ while only 20 (9.9\%) of the controls had haemoglobin level less than $10 \mathrm{mg} / \mathrm{dl}$. With regard to baseline functional status, $62(30.5 \%)$ of the cases and 43 (21.2\%) of the controls were bed ridden/ambulatory. Majority of cases $144(70.9 \%)$ were in WHO clinical stage III/IV. In contrary, only $83(40.9 \%)$ of control groups were in WHO clinical stage III/IV. In total, 147 (72.4\%) patients in cases and 85 (41.9\%) of the controls had CD4+ cell count less than 200 cells/ml. 55 (27.1\%) of the cases' ART adherence level was fair/ poor while only 3 (1.5\%) of the controls' ART adherence level was fair/poor. The most commonly used ART regimen was 1e, $81(39.9 \%)$ in cases and $89(43.9 \%)$ in controls. During ART initiation $155(76.4 \%)$ of cases and 138 (68.0\%) of controls did not use INH preventive therapy. However, majority of the cases and controls used CTX prophylaxis (Table 4).

3.4. Bivariable and Multivariable Analysis of Factors Associated with TB Infection after ART Initiation. Bivariable logistic regression analysis was done to identify potential determinants of TB infection after ART initiation. The results of bivariable logistic regression show that patient's previous TB history, baseline functional status, WHO clinical stage, haemoglobin level, CD4 cell level and adherence level, patient's family previous TB history, and IPT prophylaxis were selected as candidates for multivariable model.

However, during multivariable logistic regression, five independent variables patient's previous TB history, haemoglobin level, CD4 level, adherence level, and WHO clinical stage remained significant determinants of TB infection after ART initiation. This implies that the odd for an HIV patient on ART treatment to develop TB was related to these five independent variables. The odds of having previous $\mathrm{TB}$ history are 2.411 times $(\mathrm{AOR}=2.411 ; 95 \% \mathrm{CI}$ : $1.492,3.895$; $P$ value $<0.001)$ higher among cases than in controls; this shows that having previous TB history is positively associated or statistically significant with occurrence of TB among HIV patients after ART initiation. Similarly, the odds of HIV patients whose haemoglobin level is less than $10 \mathrm{mg} / \mathrm{dl}$ were nearly $4(\mathrm{AOR}=3.67 ; 95 \% \mathrm{CI}$ : 1.981, 6.791; $P$ value $<0.001)$ times higher among cases than in controls. This implies that having haemoglobin level less than 10 at baseline is statistically positively associated with occurrence of active TB after starting ART treatment in HIV patients. And also, the odds of HIV patients with CD4 cells count $<200$ were about $2(\mathrm{AOR}=2.023 ; 95 \% \mathrm{CI}: 1.244$, 3.290; $P$ value $=0.004)$ times higher among cases than in controls. This shows that lower CD4 less than 200 is statistically positively associated with occurrence of active TB in HIV patients after ART initiation. The odds of being on adherence level of fair/poor were 19 (AOR: 19.002; CI: 5.590, 64.593; $P$ value $<0.001)$ times higher among cases than in controls showing that being on adherence level of fair or poor was significantly associated with development of active tuberculosis among HIV patients on ART. In addition, the odds of having WHO clinical stage III/IV at start of ART were also 3 (AOR: 2.579; CI: 1.591, 4.179; $P$ value $<0.001$ ) times higher among cases than in controls; this implies that advanced WHO clinical stage is statistically significantly associated with occurrence of TB among HIV patients after ART initiation (Table 5).

\section{Discussion}

Tuberculosis is a major public health concern globally, especially in sub-Saharan African countries. It is also the most common presenting illness among people living with HIV, including those who are taking antiretroviral treatment $[2,3]$. To prevent and control TB infection among HIV 
TABLE 2: Sociodemographic characteristics of the study participants of active tuberculosis occurrence among adult HIV-positive patients after ART initiation in West Showa Zone public hospitals, Ethiopia, 2019.

\begin{tabular}{|c|c|c|c|c|}
\hline \multicolumn{2}{|c|}{ Sociodemographic characteristics of the study participants } & \multirow{2}{*}{$\begin{array}{c}\text { Cases }(n=203) \\
90(44.3 \%)\end{array}$} & \multirow{2}{*}{$\begin{array}{c}\text { Controls }(n=203) \\
92(45.3 \%)\end{array}$} & \multirow{2}{*}{$\begin{array}{c}\text { Total }(n=406) \\
182(44.8 \%)\end{array}$} \\
\hline & Male & & & \\
\hline Sex & Female & $113(55.7 \%)$ & $111(54.7 \%)$ & $224(55.2 \%)$ \\
\hline \multirow{4}{*}{ Age } & $<30$ years & $76(37.4 \%)$ & $53(26.1 \%)$ & $129(31.8 \%)$ \\
\hline & $30-39$ years & $79(38.9 \%)$ & $103(50.7 \%)$ & $182(44.8 \%)$ \\
\hline & $40-49$ years & $36(17.7 \%)$ & $33(16.3 \%)$ & $69(10.8 \%)$ \\
\hline & $\geq 50$ years & $12(5.9 \%)$ & $14(6.9 \%)$ & $26(6.4 \%)$ \\
\hline \multirow{3}{*}{ Ethnic group } & Oromo & $164(80.8 \%)$ & $181(89.2 \%)$ & $345(85.0 \%)$ \\
\hline & Amhara & $26(12.8 \%)$ & $22(10.8 \%)$ & $48(11.8 \%)$ \\
\hline & Others & $13(6.4 \%)$ & 0 & $13(3.2 \%)$ \\
\hline \multirow{3}{*}{ Religion } & Orthodox & $146(71.9 \%)$ & $118(58.1 \%)$ & $264(65.0 \%)$ \\
\hline & Protestant & $47(23.2 \%)$ & $78(38.4 \%)$ & $125(30.8 \%)$ \\
\hline & Others & $10(4.9 \%)$ & $7(3.5 \%)$ & $17(4.2 \%)$ \\
\hline \multirow{4}{*}{ Education level } & Not attending formal education & $47(23.2 \%)$ & $58(28.6 \%)$ & $105(25.9 \%)$ \\
\hline & Primary school (1-8 grades) & $93(45.8 \%)$ & $91(44.8 \%)$ & $184(45.3 \%)$ \\
\hline & Secondary school (9-12) & $47(23.2 \%)$ & $40(19.7 \%)$ & $87(21.4 \%)$ \\
\hline & Diploma or above & $16(7.9 \%)$ & $14(6.9 \%)$ & $30(7.4 \%)$ \\
\hline \multirow{4}{*}{ Marital status } & Single & $11(5.4 \%)$ & $10(5.0 \%)$ & $21(5.2 \%)$ \\
\hline & Married & $137(67.5 \%)$ & $133(65.5 \%)$ & $270(66.5 \%)$ \\
\hline & Divorced & $30(14.8 \%)$ & $34(16.7 \%)$ & $64(15.8 \%)$ \\
\hline & Widowed & $25(12.3 \%)$ & $26(12.8 \%)$ & $51(12.5 \%)$ \\
\hline \multirow{2}{*}{ Residence } & Urban & $156(76.8 \%)$ & $155(76.4 \%)$ & $311(76.6 \%)$ \\
\hline & Rural & $47(23.2 \%)$ & $48(23.6 \%)$ & $95(23.4 \%)$ \\
\hline \multirow{3}{*}{ Occupation } & Unemployed & $129(63.5 \%)$ & $129(63.5 \%)$ & $258(63.5 \%)$ \\
\hline & Government employed & $26(12.8 \%)$ & $18(8.9 \%)$ & $44(10.8 \%)$ \\
\hline & Self-employed & $48(23.7 \%)$ & $56(27.6 \%)$ & $104(25.6 \%)$ \\
\hline \multirow{2}{*}{ Family size } & $1-5$ people & $160(78.8 \%)$ & $162(79.8 \%)$ & $322(79.3 \%)$ \\
\hline & $\geq 6$ people & $43(21.2 \%)$ & $41(20.2 \%)$ & $84(20.7 \%)$ \\
\hline
\end{tabular}

Other ethnic groups include Tigre, Gurage, Sidama, and Wolaita; other religions include Wakefata and Muslim.

TABLE 3: Environmental and behavioural characteristics, comorbidity, and nutritional status of the study participants of active tuberculosis occurrence among adult HIV-positive patients after ART initiation in West Showa Zone public hospitals, Ethiopia, 2019.

\begin{tabular}{|c|c|c|c|c|}
\hline Variables & & Cases $(n=203)$ & Controls $(n=203)$ & Total $(n=406)$ \\
\hline \multicolumn{5}{|l|}{ Environmental characteristics } \\
\hline \multirow{2}{*}{ Patient's family previous TB history } & Yes & $40(19.7 \%)$ & $29(14.3 \%)$ & $69(17.0 \%)$ \\
\hline & No & $163(80.3 \%)$ & $174(85.7 \%)$ & $337(83.0 \%)$ \\
\hline \multirow{2}{*}{ Owned separate kitchen } & Yes & $194(95.6 \%)$ & $199(98.0 \%)$ & $393(96.8 \%)$ \\
\hline & No & $9(4.4 \%)$ & $4(2.0 \%)$ & $13(3.2 \%)$ \\
\hline \multirow{2}{*}{ Use of kerosene as source of energy } & Yes & $4(2.0 \%)$ & $3(1.5 \%)$ & $7(1.7 \%)$ \\
\hline & No & $199(98.0 \%)$ & $200(98.5 \%)$ & $399(98.3 \%)$ \\
\hline \multicolumn{5}{|l|}{ Behavioural characteristics } \\
\hline \multirow{2}{*}{ Chewing khat } & Yes & $14(6.9 \%)$ & $4(2.0 \%)$ & $18(4.4 \%)$ \\
\hline & No & $189(93.1 \%)$ & $199(98.0 \%)$ & $388(95.6 \%)$ \\
\hline \multirow{2}{*}{ Smoking tobacco } & Yes & $5(2.5 \%)$ & $4(2.0 \%)$ & $9(2.2 \%)$ \\
\hline & No & $198(97.5 \%)$ & $199(98.0 \%)$ & $397(97.8 \%)$ \\
\hline \multirow{2}{*}{ Drinking alcohol } & Yes & $82(40.4 \%)$ & $74(36.5 \%)$ & $156(38.4 \%)$ \\
\hline & No & $121(59.6 \%)$ & $129(63.5 \%)$ & $250(61.6 \%)$ \\
\hline \multicolumn{5}{|l|}{ Comorbidity status } \\
\hline \multirow{2}{*}{ Having asthma and/or diabetes mellitus } & Yes & $3(1.5 \%)$ & $11(5.4 \%)$ & $14(3.4 \%)$ \\
\hline & No & $200(98.5 \%)$ & $192(94.6 \%)$ & $392(96.6 \%)$ \\
\hline \multicolumn{5}{|l|}{ Nutritional status } \\
\hline \multirow{3}{*}{ BMI category } & $<18.5$ & $72(35.5 \%)$ & $69(34.0 \%)$ & $141(34.7 \%)$ \\
\hline & $18.5-25$ & $129(63.5 \%)$ & $130(64.0 \%)$ & $259(63.8 \%)$ \\
\hline & $>25$ & $2(1.0 \%)$ & $4(2.0 \%)$ & $6(1.5 \%)$ \\
\hline
\end{tabular}


TABLE 4: Clinical and immunological characteristics of the study participants of active tuberculosis occurrence among adult HIV-positive patients after ART initiation in West Showa Zone public hospitals, Ethiopia, 2019.

\begin{tabular}{|c|c|c|c|c|}
\hline \multicolumn{2}{|c|}{ Clinical and immunological characteristics } & \multirow{2}{*}{$\begin{array}{c}\text { Cases }(n=203) \\
134(66.0 \%)\end{array}$} & \multirow{2}{*}{$\begin{array}{c}\text { Controls }(n=203) \\
76(37.4 \%)\end{array}$} & \multirow{2}{*}{$\begin{array}{c}\text { Total }(n=406) \\
210(51.7 \%)\end{array}$} \\
\hline & Yes & & & \\
\hline Patient's previous TB history & No & $69(34.0 \%)$ & $127(62.6 \%)$ & $196(48.3 \%)$ \\
\hline \multirow{2}{*}{ Haemoglobin level } & $<10 \mathrm{mg} / \mathrm{dl}$ & $68(33.5 \%)$ & $20(9.9 \%)$ & $88(21.7 \%)$ \\
\hline & $\geq 10 \mathrm{mg} / \mathrm{dl}$ & $135(66.5 \%)$ & $183(90.1 \%)$ & $318(78.3 \%)$ \\
\hline \multirow{2}{*}{ Baseline functional status } & Bed ridden/ambulatory & $62(30.5 \%)$ & $43(21.2 \%)$ & $105(25.9 \%)$ \\
\hline & Working & $141(69.5 \%)$ & $160(78.8 \%)$ & $301(74.1 \%)$ \\
\hline \multirow{2}{*}{ WHO HIV/AIDS stage } & Stage I/II & $59(29.1 \%)$ & $120(59.1 \%)$ & $179(44.1 \%)$ \\
\hline & Stage III/IV & $144(70.9 \%)$ & $83(40.9 \%)$ & $227(55.9 \%)$ \\
\hline \multirow{2}{*}{ CD4 level } & $<200$ cells $/ \mathrm{ml}$ & $147(72.4 \%)$ & $85(41.9 \%)$ & $232(57.1 \%)$ \\
\hline & $\geq 200$ cells $/ \mathrm{ml}$ & $56(27.6 \%)$ & $118(58.1 \%)$ & $174(42.9 \%)$ \\
\hline \multirow{2}{*}{ Adherence level } & Good & $148(72.9 \%)$ & $200(98.5 \%)$ & $348(85.7 \%)$ \\
\hline & Fair/poor & $55(27.1 \%)$ & $3(1.5 \%)$ & $58(14.3 \%)$ \\
\hline \multirow{5}{*}{ Baseline ART regimen } & $\mathrm{d} 4 \mathrm{~T}+3 \mathrm{TC}+\mathrm{NVP}$ & $23(11.3 \%)$ & $25(12.3 \%)$ & $48(11.8 \%)$ \\
\hline & $\mathrm{d} 4 \mathrm{~T}+3 \mathrm{TC}+\mathrm{EFV}$ & $20(9.9 \%)$ & $16(7.9 \%)$ & $36(8.9 \%)$ \\
\hline & $\mathrm{AZT}+3 \mathrm{TC}+\mathrm{EFV}$ & $44(21.7 \%)$ & $51(25.1 \%)$ & $95(23.4 \%)$ \\
\hline & $\mathrm{ZDV}+3 \mathrm{TC}+\mathrm{EFV}$ & $35(17.2 \%)$ & $22(10.8 \%)$ & $57(14.0 \%)$ \\
\hline & $\mathrm{TDF}+3 \mathrm{TC}+\mathrm{EFV}$ & $81(39.9 \%)$ & $89(43.9 \%)$ & $170(41.9 \%)$ \\
\hline \multirow{2}{*}{ Used IPT prophylaxis } & Yes & $48(23.6 \%)$ & $65(32.0 \%)$ & $113(27.8 \%)$ \\
\hline & No & $155(76.4 \%)$ & $138(68.0 \%)$ & $293(72.2 \%)$ \\
\hline \multirow{2}{*}{ Used CTX prophylaxis } & Yes & $200(98.5 \%)$ & $188(92.6 \%)$ & $388(95.6 \%)$ \\
\hline & No & $3(1.5 \%)$ & $15(7.4 \%)$ & $18(4.4 \%)$ \\
\hline
\end{tabular}

TABLE 5: Multivariable logistic regression analysis of significant determinants of TB infection after ART initiation in public hospitals of West Showa Zone, 2019.

\begin{tabular}{|c|c|c|c|c|c|c|}
\hline Variables & & Cases & Controls & COR $(95 \% \mathrm{CI})$ & $\operatorname{AOR}(95 \% \mathrm{CI})$ & $P$ value \\
\hline \multirow{2}{*}{ Patient's previous TB history } & Yes & 134 & 76 & $3.25(2.16,4.87)$ & $2.41(1.49,3.90)$ & \multirow{2}{*}{$<0.001$} \\
\hline & No & 69 & 127 & 1 & 1 & \\
\hline \multirow{2}{*}{ Haemoglobin level } & $<10 \mathrm{~g} / \mathrm{dl}$ & 68 & 20 & $4.61(2.67,7.96)$ & $3.67(1.98,6.79)$ & \multirow{2}{*}{$<0.001$} \\
\hline & $\geq 10 \mathrm{~g} / \mathrm{dl}$ & 138 & 183 & 1 & 1 & \\
\hline \multirow{2}{*}{ CD4 level } & $<200$ cells $/ \mathrm{ml}$ & 147 & 85 & $3.64(2.41,5.52)$ & $2.02(1.24,3.29)$ & \multirow{2}{*}{0.004} \\
\hline & $\geq 200$ cells $/ \mathrm{ml}$ & 56 & 118 & 1 & 1 & \\
\hline \multirow{2}{*}{ Adherence level } & Fair/poor & 55 & 3 & $24.78(7.60,80.73)$ & $19.0(5.59,64.59)$ & \multirow{2}{*}{$<0.001$} \\
\hline & Good & 148 & 200 & 1 & 1 & \\
\hline \multirow{2}{*}{ WHO clinical stage } & Stage III/IV & 144 & 83 & $3.53(2.34,5.33)$ & $2.58(1.59,4.18)$ & \multirow{2}{*}{$<0.001$} \\
\hline & Stage I/II & 59 & 120 & 1 & 1 & \\
\hline
\end{tabular}

${ }^{1}$ Reference category.

patients following ART this study was aimed at identifying determinants of active tuberculosis occurrence among adult HIV-positive patients after ART initiation in West Showa Zone public hospitals, Ethiopia.

The result of this study showed that patients' previous history of tuberculosis was an independent determinant for the occurrence of active tuberculosis. Patients who have previous history of TB were nearly two times more likely to develop TB compared to those who did not have previous TB history. Similar findings were reported from previous studies done on similar topic in Iran and Abidjan subSaharan Africa [12-14]. Thus, having previous TB history increases the risk of developing TB for HIV patient on ART treatment. This might be due to the recurrence of the tuberculosis bacterium when the patient condition is not good or when the patient's immunity is compromised.
Another independent determinant factor of active tuberculosis was advanced WHO clinical stage (III or IV); patients with WHO stage III or IV have higher risk of developing TB than those with WHO stage I or II. This result is consistent with other studies done in Tanzania, Nigeria, India, and South Africa [15-18], and similar results were also reported from studies conducted in our country Ethiopia $[2,5]$. This result suggests that patients who had advanced WHO clinical stage (III or IV) might be immune-compromised and predisposed to $\mathrm{TB}$ easily or acquire tuberculosis more than others.

In addition, patients having haemoglobin level of $<10 \mathrm{mg} / \mathrm{dl}$ were at higher risk of developing TB than those having haemoglobin level $\geq 10 \mathrm{mg} / \mathrm{dl}$ similar to other study findings done in Nigeria [16]. This might be due to iron deficiency's association with decreased cellular immunity, which may predispose HIV 
patients with lower haemoglobin level to risk of developing tuberculosis.

This study result indicated that CD4 cell count less than 200 cells $/ \mathrm{mm}^{3}$ substantially increased the risk of developing TB in people living with HIV. This finding is in line with several other research results done in Ethiopia, in different African countries, and in Europe as well as North America $[5,10,12,15-17,19-21]$. The reason could be as the CD4 decreases, viral load increases and WHO clinical stage advances. Studies done in Germany and Nigeria reported that increased viral load is risk factor for TB occurrence [16, 21]. Therefore, lower CD4 cell counts increase the risk of developing TB for HIV patients following ART.

A study has reported that poor ART adherence level has an association with the occurrence of TB among PLHIV [16]. This study finding also confirmed the existence of significant association between ART adherence level and occurrence of TB. The odd of the case patients being on fair/ poor ART adherence level was 19 times greater than control patients. Therefore, fair/poor ART adherence level is significantly associated with TB occurrence among PLHIV. The reason could be the following: if patients do not take ART medication with good adherence, their viral load increases. As a consequence, patients whose viral load is not suppressed most likely develop TB due to their compromised immune.

According to this study result behavioural characteristics such as drinking alcohol, chewing khat, and smoking tobacco were not associated with occurrence of TB in PLHIV which is in line with case-control study conducted in Addis Ababa regarding smoking [2]. However, previous studies done in Addis Ababa and Arba Minch show that alcohol drinking and chat chewing were associated with occurrence of TB among people living with HIV after ART initiation $[2,4]$. This difference might be due to low prevalence of patients with these behaviours in this study and also there could be a social desirability bias whereby participants denied their behavioural status.

Previously, a study done in Burkina Faso shows that overcrowding was associated with $\mathrm{TB}$ occurrence after ART initiation in PLWH [14]. However, in this study, overcrowding was not associated with occurrence of TB which is in line with study done in Addis Ababa [2]. This might be because of the reason that majority of this study participants (79.3\%) were living in the household with 5 or less people. Therefore, the effect of overcrowding in this particular study cannot be seen.

Similarly, in previous study done in Addis Ababa, using kerosene in the house for source of energy was associated with TB occurrence among people living with HIV after ART initiation [2]. However, this was not the case in this study since only $1.7 \%$ of the study participants used kerosene for source of energy. Therefore, in this study, with this rare prevalence of kerosene use it is impossible to investigate its association with TB occurrence after ART initiation among PLHIV.

\subsection{Limitations of the Study}

(i) With a case-control study design that we used, we cannot measure TB incidence among PLHIV. Thus, further study could be done using cohort study design to measure TB incidence.

(ii) Due to incomplete data, some study subjects were excluded from the study that might alter the finding of this study.

(iii) Patients who were transferred out to other health centres were excluded from the study. If these patients have different characteristics, the study findings can possibly be altered.

(iv) In Ethiopia, ART services are provided at hospitals and health centres. However, due to financial constraints, we could not include health centres that can possibly have patients with different characteristicscompared to patients in our study. Therefore, future research should be carried out widening the scope of the study to the lower level health services to validate the findings.

\section{Implications of the Study}

Different stakeholders such as government, health professions, researchers, and community will be benefitted from findings of this study.

First, findings of the study will provide information for the policy makers to develop strategies and guidelines for scaling up prevention of TB in PLHIV to address TB-HIV comorbidity and mortality. Second, the results of this study are important for health professionals working on ART clinic to build up knowledge on the areas in order to provide health education and awareness creation about TB prevention and control among PLHIV. They can also use the findings for prioritizing TB screening among PLHIV. Third, the findings of this study will contribute to the strategies of improving quality of life and well-being of PLHIV. Lastly, the findings ofthis study will help researchers interested in the field by providing information regarding determinants of TB among PLHIV in the study area.

\section{Conclusion and Recommendations}

6.1. Conclusion. In conclusion, in this study having previous TB history, low haemoglobin level, low CD4 count, fair/poor adherence level to ART, and WHO clinical disease stage III/ IV were identified as significant determinants for the occurrence of active tuberculosis among people living with HIV/AIDS following ART.

6.2. Recommendations. Based on the main findings of this study, the following recommendations were forwarded to the hospitals in the administrative zone to reduce TB burden among HIV patients on ART.

(i) Early HIV/AIDS screening program and early initiation of ART should be targeted

(ii) Early haemoglobin level screening for HIV patient should be done to recommend intervention

(iii) Special emphasis should be given to HIV patients who have previous TB history 
(iv) Awareness should be given to HIV patients about importance of good adherence level to ART

\section{Abbreviations}

AIDS: Acquired immune deficiency syndrome

AOR: Adjusted odds ratio

ART: Antiretroviral therapy

COR: Crude odds ratio

CPT: Cotrimoxazole preventive therapy

HAART: Highly active antiretroviral therapy

HIV: Human immunodeficiency virus

IPT: Isoniazid preventive therapy

MUAC: Mid-upper arm circumference

PLHIV: People living with human immunodeficiency virus

SPSS: $\quad$ Statistical Package for Social Sciences

TB: Tuberculosis

WHO: World Health Organization.

\section{Data Availability}

Data used to support the findings of this research can be obtained upon request from the corresponding author.

\section{Conflicts of Interest}

There are no potential conflicts of interest to disclose in this study.

\section{Acknowledgments}

We are very grateful to the selected hospitals' managers who allowed us to conduct this study.

\section{References}

[1] World Health Organization, Global Tuberculosis Report, World Health Organization, Geneva, Switzerland, 2018.

[2] K. T. Kibret, A. W. Yalew, B. G. Belaineh, and M. M. Asres, "Determinant factors associated with occurrence of tuberculosis among adult people living with HIV after antiretroviral treatment initiation in Addis Ababa, Ethiopia: a case control study," PLoS One, vol. 8, no. 5, Article ID e64488, 2013.

[3] Ethiopia Federal Ministry of Health, National Guidelines for Comprehensive HIV Prevention, Care and Treatment, Ethiopia Federal Ministry of Health, Addis Ababa, Ethiopia, 2014.

[4] M. Dalbo and A. Tamiso, "Incidence and predictors of tuberculosis among HIV/AIDS infected patients: a five-year retrospective follow-up study," Advances in Infectious Diseases, vol. 6, no. 02, pp. 70-81, 2016.

[5] H. Melkamu, B. Seyoum, and Y. Dessie, "Determinants of tuberculosis infection among adult HIV positives attending clinical care in western Ethiopia: a case-control study," AIDS Research and Treatment, vol. 2013, Article ID 279876, 7 pages, 2013.

[6] S. Fekadu, W. Teshome, and G. Alemu, "Prevalence and determinants of tuberculosis among HIV infected patients in South Ethiopia," The Journal of Infection in Developing Countries, vol. 9, no. 08, pp. 898-904, 2015.

[7] Ethiopian Health and Nutrition Research Institute, National TB/HIV Sentinel Surveillance Report, Ethiopian Health and Nutrition Research Institute, Addis Ababa, Ethiopia, 2013.
[8] Ethiopian Public Health Institute, National TB/HIV Sentinel Surveillance Report, Ethiopian Public Health Institute, Addis Ababa, Ethiopia, 2015.

[9] S. Rajasekaran, K. Raja, L. Jeyaseelan et al., "Post-HAART tuberculosis in adult and adolescents with HIV in India: incidence, clinical and immunological profile," Indian Journal of Tuberculosis, vol. 56, no. 2, pp. 69-76, 2009.

[10] D. Addisu and E. Wubshet, "Magnitude and determinants of opportunistic infections among HIV/aAIDS patients in sphmmc, Addis Ababa, Ethiopia: retrospective study," Juniper Online Journal of Public Health, vol. 4, no. 1, pp. 1-8, 2018.

[11] I-TECH Ethiopia, HIV Case Management in Ethiopia: A Pragmatic Approach to Maximizing Adherence to Long-Term Treatment and Retention in Chronic Illness Care, I-TECH Ethiopia, Addis Ababa, Ethiopia, 2017.

[12] L. Molaeipoor, J. Poorolajal, M. Mohraz, and N. Esmailnasab, "Predictors of tuberculosis and human immuno deficiency virus Co- infection: a case control study," Epidemiology and Health, vol. 36, pp. 1-6, 2014.

[13] C. Seyler, S. Toure, E. Messou, D. Bonard, D. Gabillard, and X. Anglaret, "Risk factors for active tuberculosis after antiretroviral treatment initiation in abidjan," American Journal of Respiratory and Critical Care Medicine, vol. 172, no. 1, pp. 123-127, 2005.

[14] Z. C. Méda, I. Sombié, O. W. C. Sanon, D. Maré, D. E. Morisky, and Y.-M. A. Chen, "Risk factors of tuberculosis infection among HIV/AIDS patients in Burkina Faso," AIDS Research and Human Retroviruses, vol. 29, no. 7, pp. 1045-1055, 2013.

[15] E. Liu, A. Makubi, P. Drain et al., "Tuberculosis incidence rate and risk factors among HIV-infected adults with access to antiretroviral therapy," AIDS, vol. 29, no. 11, pp. 1391-1399, 2015.

[16] C. A. Chang, S. T. Meloni, G. Eisen et al., "Tuberculosis incidence and risk factors among human immunodeficiency virus (HIV)-Infected adults receiving antiretroviral therapy in A large HIV program in Nigeria," Open Forum Infectious Diseases, vol. 2, no. 4, p. ofv154, 2015.

[17] K. Bhuvana, N. Hema, and R. Patil, "Prevalence and risk factors for opportunistic infections in HIV patients who developed adverse drug reactions (ADRs) to antiretroviral therapy (ART) in A tertiary-care teaching hospital," National Journal of Physiology, Pharmacy and Pharmacology, vol. 5, no. 3, pp. 200-206, 2015.

[18] S. D. Lawn, M. Badri, and R. Wood, "Tuberculosis among HIV-infected patients receiving HAART: long term incidence and risk factors in A South African cohort," AIDS, vol. 19, no. 18, pp. 2109-2116, 2005.

[19] E. Girardi, M. J. Gill, A. Monforte, and F. Dabis, "Incidence of tuberculosis among HIV-infected patients receiving highly active antiretroviral therapy in Europe and North America," Clinical Infectious Diseases, vol. 41, no. 12, pp. 1772-1782, 2005.

[20] D. W. Gunda, S. C. Maganga, I. Nkandala et al., "Prevalence and risk factors of active TB among adult HIV patients receiving ART in northwestern Tanzania: a retrospective cohort study," Canadian Journal of Infectious Diseases and Medical Microbiology, vol. 2018, Article ID 1346104, 7 pages, 2018.

[21] B. Karo, W. Haas, C. Kollan, B. Gunsenheimer-Bartmeyer, O. Hamouda, and L. Fiebig, "Tuberculosis among people living with HIV/AIDS in the German clinsurv HIV cohort: long-term incidence and risk factors," BMC Infectious Diseases, vol. 14, no. 1, pp. 1-12, 2014. 